Original Article

\title{
Specific rehabilitation exercise for the treatment of patients with chronic low back pain
}

\author{
Michaela Tomanova, MD ${ }^{1,3)^{*}}$, Marcela Lippert-Grüner ${ }^{2)}$, Lenka Lhotska ${ }^{3)}$ \\ 1) Rehabilitation Clinic Brandýs nad Orlicí: Lázeňská 58, 56112 Brandýs nad Orlicí, Czech Republic \\ 2) School of Health and ANR Bonn, Medizinische Fakultät der Universität zu Köln, Germany \\ 3) Czech Technical University, Czech Republic
}

\begin{abstract}
Purpose] To evaluate the efficacy of our special rehabilitation method for patients with low back pain (LBP). [Subjects and Methods] All participants ( $\mathrm{n}=33$ ) received at least five individual 30-minute therapy sessions per week using the INFINITY method ${ }^{\circledR}$ and six group therapy sessions per week in a gymnasium and swimming pool, each lasting 30 minutes and including the INFINITY method ${ }^{\circledR}$. The treatment lasted between four to seven weeks. Plantar function using a graphic method (computer plantography), graphical quantification of postural control during static standing (posturography), and pain were measured and evaluated before and after rehabilitation therapy. The INFINITY method ${ }^{\mathbb{R}}$ is a special rehabilitation method for patients with musculoskeletal problems. The method focuses on stabilization and strengthening of the trunk, dorsal and abdominal muscles, including the deep stabilization system which is closely linked with diaphragmatic breathing. It teaches the central nervous system to control muscles more precisely. [Results] Plantar functions, postural control in the upright stance and pain of LBP patients were significantly improved by $4-7$ weeks of rehabilitation treatment with the INFINITY method ${ }^{\circledR}$. There were significant differences in all measured dependent variables of the patients between before and after treatment. [Conclusion] Rehabilitation therapy with the INFINITY method ${ }^{\circledR}$ positively influences body stabilization and pain in patients with problems of the lumbar spine. This method presents a new improved approach (with enhanced effect) to rehabilitation therapy for LBP patients.

Key words: Rehabilitation method, Plantography, Posturography
\end{abstract}

(This article was submitted Oct. 3, 2014, and was accepted Nov. 28, 2014)

\section{INTRODUCTION}

At present, low back pain (LBP) is a great social and economic problem because the ongoing prevalence of this condition is between $60-85 \%$, and its incidence has been increasing in developed countries since the second half of the last century ${ }^{1)}$. The highest incidence of LBP is observed in patients between $30-35$ years of age ${ }^{2}$. From many randomized studies, it is clear that not only prevention, but in particular follow-up care of LBP patients must include regular physical activity together with appropriately indicated rehabilitation, which does not strain the musculoskeletal system ${ }^{3}$. If a patient is susceptible to dysfunction of the neurological system, additional ways of treatment should include other appropriate therapy methods, including surgery. Early and correct diagnosis is essential to establish the severity of patients' conditions ${ }^{4,5}$ ).

Currently, there is no precise definition of chronic low back pain. In some cases, chronic problems are defined as

\section{*Corresponding author. Michaela Tomanova (E-mail:} sekretariat@rehabilitacniustav.cz)

(C2015 The Society of Physical Therapy Science. Published by IPEC Inc. This is an open-access article distributed under the terms of the Creative Commons Attribution Non-Commercial No Derivatives (by-ncnd) License $<$ http://creativecommons.org/licenses/by-nc-nd/3.0/> . pain that lasts longer than 7-12 weeks. Others define it as pain that persists longer than expected with conventional treatment. Generally, it can be classified as frequently recurring back pain, which intermittently affects individuals over an extended period of time ${ }^{6}$.

In many LBP patients, it is often difficult to properly diagnose and identify the cause, despite the significant advances in currently available diagnostic methods. In some cases, it is difficult to clearly connect the results of imaging methods, the subjective symptoms described by the patient, and changes in the pathology of the musculoskeletal system ${ }^{7)}$. Another complication for making a correct diagnosis is the fact that LBP can have a variety of different etiologies. The most significant ethiopathogenetic factors of vertebrogenic dysfunctions cited by Richardson et al. ${ }^{7)}$ include disorders of the deep stabilization systems of the spine (DSS). The deep stabilization system of the spine is responsible for stabilization of the spine as well as the entire body during movement and under static pressure ${ }^{7)}$. When it is compromised or weakened, the entire body is destabilized, while some muscle structures can be overload and others can be weakened including the deep stabilization system.

Even at present, when a great variety of different diagnostic tools are available, we cannot accurately elucidate the connection between objective findings during physical examination, subjective complaints of the patient and discrepancies between them. According to Ricci et al., approxi- 
mately $39 \%$ of patients suffer from herniated disc and do not describe any subjective complaints, and during radiculography protrusion of the intervertebral disc was found in $50 \%$ of cases and herniation of the disc in $24 \%$ of cases, data in a study on workers in the USA ${ }^{8}$. To our knowledge, similar research evaluating the effects of rehabilitation using plantography and posturography has not been performed in the past. We hypothesized that there would be certain differences in all measured values of patients before and after treatment with the INFINITY method ${ }^{\circledR}$. The purpose of this study was to verify the presence of differences between the measured values of the center of force (COF) and subjective pain described by a visual analogue scale (VAS) in patients with LBP before and after rehabilitation therapy, and used the results to evaluate the efficacy of our special rehabilitation method for the treatment of patients with LBP.

\section{SUBJECTS AND METHODS}

All participants read and signed an informed consent form, and the study was approved by the Ethics Committee of the Rehabilitation Clinic Brandys nad Orlici. This study used a quasi-experimental design to address the study purpose. Patients with the diagnosis of LBP who were treated at the Rehabilitation Clinic Brandys nad Orlici from February to November 2013 were evaluated. The length of their treatment was four to seven weeks. The goal was to confirm the efficacy of our rehabilitation therapy, the INFINITY method $^{\circledR}$. During the study period, a total of 198 patients were treated and examined using a MatScan device (Tekscan Inc., South Boston, Massachusetts, USA). Thirty-three patients from this group were selected randomly. All these patients suffered from LBP and the most frequent causes of the pain were: osteochondrosis, spondylarthrosis, and spondylosis. The ratio of females to males was $8: 3$. The ages of the females and males in this group were $64.42 \pm 11.52$ and $58.33 \pm 12.11$ years, respectively. All the patients received at least five individual 30-minute therapy sessions per week using the INFINITY method ${ }^{\circledR}$, and six group therapy sessions per week in the gymnasium and swimming pool, with each session lasting 30 minutes and including the INFINITY $\operatorname{method}^{\circledR}$. The INFINITY method ${ }^{\circledR}$ is a special rehabilitation method developed at the Rehabilitation Clinic Brandys nad Orlici. It is used for the rehabilitation of patients with musculoskeletal problems. Its name comes from the English word "infinity" because it utilizes movement in the shape of the infinity sign in part of the exercises. The method focuses on stabilization and strengthening of trunk muscles, dorsal and abdominal muscles, including the deep stabilization system closely linked with diaphragmatic breathing. It contributes to increasing body mobility and flexibility based on relaxation, extension, and mobilization of the soft tissues of the motor system. It activates subconscious and conscious setting of the postural system of the body, efficiently involves the stabilization system of the spine, and does not overload musculo-fibrous tissues. It teaches the central nervous system to control muscles more precisely. The method uses active movement and/or passive movement and passive techniques. The method uses three types of $3 \mathrm{D}$ movements. The first is called macro-movement (in a range of centimeters) and it resembles Tai-Chi. The second is called micro-movement (in a range of millimeters) and it is especially designed for patients with significant pain and patients with limited movement range (either because of inability or restriction due to medical indication). Micromovement is a fine movement that minimally loads the motor system, improves muscle activity and trains the higher motor centers in the central nervous system. The third type of movement is movement with visualization during which the patient only imagines the movement. One of the advantages of the INFINITY method ${ }^{\circledR}$ is that the treatment can be applied even in the acute phase when a patient may be suffering from intense pain, and that it offers extended variability of auto-therapeutic exercises. The therapy includes special exercises and training of breathing, which allow both muscle relaxation and activation of several muscle groups, including the deep stabilization system, as well as improving psychological factors. We evaluated the efficacy of the rehabilitation therapy using the MatScan pressure mat system. At the beginning and at the end of the intervention, the patients were evaluated using plantography and posturography. The measurements were carried out with the patients standing upright with their eyes open. We compared the values measured before and after the intervention with the INFINITY $\operatorname{method}^{\circledR}$. Measurements were taken for 30 seconds with a scan frequency of $30 \mathrm{~Hz}$. The MatScan objectively evaluates the standing stability of the patients. Balance of the body is quantified by monitoring fluctuations of the coordinate center of supporting forces. Different authors identify this center differently. For example, Brumagne et al. ${ }^{9)}$ use the notation Center of Foot Pressure (CoP). In our case, we use the notation Center of Force (COF). The patients' plantar function was evaluated using a graphic method (computer plantography) which graphically quantifies postural control during quiet upright standing (posturography). The variables measured were: bilateral pressure on the right and left soles of the feet, gravitational forces between both soles, anteroposterior (A-P) and mediolateral (M-L) displacement of $\mathrm{COF}$, the center of gravity of the body between both soles of the feet. Using the Sway Analysis Module (SAM), we measured the area within which the values of COF, A-P and $\mathrm{M}-\mathrm{L}$ excursion of $\mathrm{COF}$ moved in a defined time interval (30 seconds). The shift in COF and difference in the COF area between pre- and post-intervention were calculated. For measurement of subjective pain of patients, a visual analogue scale (VAS) was used. VAS has been used by many authors and is considered a reliable assessment of pain. A scale of $10 \mathrm{~cm}$ in length was divided into ten equally long sections and numbered from 0 on the left side for "no pain" to 10 on the right side for "very severe pain". VAS values between $0-4$ were considered tolerable pain ${ }^{10)}$. Subjective pain was evaluated before and after the special rehabilitation treatment. Verbal instructions were given to each participant before each measurement. Values of pain before and after treatment were averaged separately and subsequently compared. Data were checked and no model assumptions of statistical tests were violated. Data were analyzed using the paired t-test for the parametric tests and Wilcoxon SignedRank Test was used to analyze the VAS data. Descriptive statistics for the outcome measures are presented as mean 
\pm standard deviation (SD). The statistical power of the tests was 0.8 for the differences in the variables noted in this study. Statistical significance was based on an alpha level set at 0.05 , furthermore the median difference and the $95 \%$ confidence intervals were calculated. The statistical analyses were performed using the statistical package SPSS for Windows, Version 22.0 (IBM, Armonk, NY, USA).

\section{RESULTS}

Thirty-three subjects met the inclusion criteria. The demographic characteristics of the individuals are shown in Table 1. All the measured values of the test group of the LBP patients showed statistically significant differences $(p=0.001)$ after treatment. Six dependent variables were statistically evaluated. Five of these parameters were related to plantographic and posturographic measurements, which showed decreases in measured values (Table 2). There were significant differences between pre- and post-rehabilitation treatment in the antero-posterior direction of movement of the COF $(\mathrm{p}<0.001)$, medial-lateral movement of the COF $(p<0.001)$, the area covered $(p<0.001)$, the COF distance $(\mathrm{p}<0.001)$, and the variation of COF $(\mathrm{p}<0.001)$. The sixth assessed dependent variable was pain which also showed a statistically significant reduction $(\mathrm{p}<0.001)$.

The results of this study show that the rehabilitation treat-

Table 1. Characteristics of patients with low back pain

\begin{tabular}{lc}
\hline Gender & \\
Females & $24(72.7 \%)$ \\
Males & $9(27.3 \%)$ \\
Mean age (SD) & \\
Females & $64.42 \pm 11.52$ \\
Males & $58.33 \pm 12.11$ \\
Number of improved items & \\
5 (all) & $20(60.6 \%)$ \\
4 & $5(15.2 \%)$ \\
3 & $6(18.2 \%)$ \\
2 & $2(6 \%)$ \\
VAS (visual analog scale) & \\
Better & $30(90.9 \%)$ \\
Same & $3(9.1 \%)$ \\
\hline SD: standard deviation &
\end{tabular}

SD: standard deviation ment of patients using the INFINITY method ${ }^{\circledR}$ resulted in statistically significant improvements in the observed plantographic and posturographic parameters of stance stability and reduced subjectively reported pain as measured by VAS, which can also be considered to be a significant improvement in the patients' overall health.

The patient group was further divided into two groups: patients with radiculopathy $(\mathrm{n}=8)$, and patients without radiculopathy $(\mathrm{n}=25)$. Using the t-test, we compared the results of both groups. In both groups we found statistically significant changes in VAS pain. Although most of the patients with radiculopathy showed improved values of measured parameters after treatment, we did not find statistically significant changes for most of the parameters of posturography measurement. In patients with radiculopathy, we succeeded in achieving stabilization of the lower back region, which was shown by the statistically significant decrease in VAS pain. However, several patients retained trigger points in the area of the hamstrings, gluteus medius and minimus, and musculus quadriceps femoris, which could have resulted in imbalance in the measured posturographic parameters.

We also divided the subjects according to age into two groups: patients younger than sixty years $(n=13)$ and patients over sixty years $(n=20)$. In both groups there were statistically significant changes in VAS pain. However, we did not find statistically significant changes in most of the parameters measured in posturography in the younger group, in contrast to the older group of patients. This may be because the younger patients were treated for a shorter time (due to work reasons) than the older patients. Thus, the younger patients did not achieve the maximum possible improvement in their health state.

\section{DISCUSSION}

Timely and correct diagnosis of low back pain is important. Various randomized studies have demonstrated the efficacy of maintaining the physical activity of patients with low back pain. Rehabilitation therapy is recommended as back pain onset prevention as well as treatment of patients who already suffer from pain. For acute pain, it is also recommended to initiate treatment with non-opioid analgesics or nonsteroidal anti-inflammatory drugs ${ }^{1}$. For restoration of locomotion, it is advisable to choose an individual rehabili-

Table 2. Plantographic and posturographic parameters—results of the paired samples test

\begin{tabular}{|c|c|c|c|c|c|}
\hline \multirow{3}{*}{ Dependent variables } & \multicolumn{5}{|c|}{ Paired differences } \\
\hline & \multirow{2}{*}{ Mean } & \multirow{2}{*}{$\begin{array}{l}\text { Standard } \\
\text { deviation }\end{array}$} & \multirow{2}{*}{$\begin{array}{l}\text { Standard } \\
\text { error mean }\end{array}$} & \multicolumn{2}{|c|}{$\begin{array}{c}95 \% \text { Confidence interval } \\
\text { of the difference }\end{array}$} \\
\hline & & & & Lower & Upper \\
\hline AP before - after & 0.94255 & 0.95116 & 0.16558 & 0.60529 & $1.27982 *$ \\
\hline ML before - after & 1.17618 & 1.23313 & 0.21466 & 0.73894 & $1.61343 *$ \\
\hline Area before - after & 2.30468 & 2.99912 & 0.52208 & 1.24123 & $3.36812^{*}$ \\
\hline Distance before - after & 7.67970 & 11.04621 & 1.92290 & 3.76288 & $11.59651^{*}$ \\
\hline Variation before - after & 0.0091645 & 0.0121416 & 0.0021136 & 0.0048593 & $0.0134698 *$ \\
\hline
\end{tabular}

AP: anteroposterior directions; ML: mediolateral directions

* Statistically significant $(\mathrm{p}<0.001)$ 
tation program which the patient can continue at home after proper training with a physiotherapist. The rehabilitation program should focus on strengthening the deep stabilizer muscles of the spine and stretching and relaxing muscles and connective tissues ${ }^{7}$. However, if the patient suffers from acute pain, severe chronic pain, or already has some other physical limitations, the usual rehabilitation treatment cannot always be started immediately. The results of clinical studies confirm the statistically significant efficacy of our rehabilitation therapy INFINITY method ${ }^{\circledR}$ for patients with LBP. The present study demonstrated that the therapy not only effectively reduces pain, but also, the measured COF parameters show, that this therapy can effectively center and stabilize the entire posture.

Dufour et al. ${ }^{11)}$ in their study evaluated two selected rehabilitation methods using VAS. Changes in VAS pain were statistically significant in both cases and the improvements ranged from 20 to $30 \%$. With the INFINITY method ${ }^{\circledR}$, we achieved statistically significant improvements of $46.6 \%$ on average, and compared to conventional methods, the INFINITY method ${ }^{\circledR}$ achieved 16.6 to $26.6 \%$ better improvement in the treatment of patients with LBP. This difference could be due to our rehabilitation treatment approach. Yoo et al. ${ }^{12)}$ compared the effect of core stabilization exercises, which are similar to the body stabilization used by the INFINITY method ${ }^{\circledR}$ using VAS for comparison. They found there were statistically significant differences between values of VAS before and after exercise in similar patient sets. Their results are in agreement with our results of a decrease in the VAS value of patients after rehabilitation. Han et al. ${ }^{13)}$ reported a statistically significant decrease of VAS of $52.1 \%$ in patients with LBP after aquatic therapy. In the present study, we achieved a decrease of VAS of almost $47 \%$.

Lee et al. ${ }^{14)}$ utilized posturography for the comparison of patients with LBP with a control group of healthy individuals. In their study, they mainly found significant differences in A-P excursion of COF between patients and the control group. Our results are in agreement with their findings.

Hsieh et al. ${ }^{15)}$ verified the effectiveness of four different standard methods used for the treatment of patients with LBP using VAS as the evaluation measure. After three weeks of rehabilitation treatment, all four groups showed significant improvements of 1.08 to $2.01 \mathrm{~cm}$ on average on the VAS. In the present study, we achieved statistically significant improvements of $2.5 \mathrm{~cm}$ on the VAS on average. We think that the difference between the results of previously conducted studies and our study lies mainly in the movement therapy, especially the micro-movements, both passive and/or active movements in the range of millimeters.

Therapy and exercises place load on the musculoskeletal apparatus without overloading it and the activation occurs simultaneously often with relaxation of these structures. Especially during the 1980s and 1990s, many studies on the effectiveness of rehabilitation for patients with LBP were conducted as this condition was (and still is) associated with great social and economic problems. Hamaoui et al. and Popa et al. ${ }^{16,17)}$ reviewed 69 case reports and their various treatments as well as the quality of their implementation and evaluation. These studies provide an overview of basic methods that are used in the treatment of patients with LBP and their potential positive effects. For comparison with the results of our study, we chose case studies that had a similar focus and design. All these studies investigated the effectiveness of certain rehabilitation methods that were more or less proven to be successful. This study demonstrated the superior efficacy of our special rehabilitation method compared to the results of previously conducted studies assessing the effects of commonly used methods of rehabilitation treatment for patients with LBP. This study was limited by the fact that the results were partially influenced by cotherapies such as electrotherapy, hydrotherapy, or massages, which the patients received in addition to the rehabilitation therapy. Certain improvements may occur even when using conventional methods of treatment, as evidenced by the results of other studies carried out on groups of patients with LBP. However, our results showed greater improvements in the monitored parameters including pain. Therefore, we think that the use of the INFINITY method ${ }^{\circledR}$ achieves better results in the treatment of patients with LBP. Given the large number of options in active and passive exercises and therapies, patients confirmed to us that the method was fun and body reshaping. They reported that they would continue to exercise after the end of treatment thanks to the large number of exercises which they can perform at home.

In conclusion, after the rehabilitation therapy, the evaluated patients demonstrated significant improvements in objectively monitored posturography and plantography measurement parameters. In addition, the patients reported subjective pain reduction as measured by the visual analogue scale. Our goal was to achieve optimal balance of structure and function of the patients' musculoskeletal systems. This study proved that application of the INFINITY method ${ }^{\circledR}$ improves stabilization, centralization, postural correction of the body, and distribution of weight on the foot soles, and it fully improves the position of the center of force. In the future, we anticipate further objective evaluation of the effectiveness of therapeutic methods using advanced sensor device(s) for measurement.

\section{REFERENCES}

1) Waddell G: The back pain revolution, 2nd ed. London: Churchill Livingstone, 2004.

2) Bonetti $\mathrm{M}$, Fontana $\mathrm{A}$, Cotticelli $\mathrm{B}$, et al.: Intraforaminal $\mathrm{O}(2)-\mathrm{O}(3)$ versus periradicular steroidal infiltrations in lower back pain: randomized controlled study. AJNR Am J Neuroradiol, 2005, 26: 996-1000. [Medline]

3) Krismer M, van Tulder M, Low Back Pain Group of the Bone and Joint Health Strategies for Europe Project: Strategies for prevention and management of musculoskeletal conditions. Low back pain (non-specific). Best Pract Res Clin Rheumatol, 2007, 21: 77-91. [Medline] [CrossRef]

4) Rocchi L, Chiari L, Cappello A, et al.: Identification of distinct characteristics of postural sway in Parkinson's disease: a feature selection procedure based on principal component analysis. Neurosci Lett, 2006, 394: 140-145. [Medline] [CrossRef]

5) Koes BW, van Tulder MW, Ostelo R, et al.: Clinical guidelines for the management of low back pain in primary care: an international comparison. Spine, 2001, 26: 2504-2513, discussion 2513-2514. [Medline] [CrossRef]

6) Freburger JK, Holmes GM, Agans RP, et al.: The rising prevalence of chronic low back pain. Arch Intern Med, 2009, 169: 251-258. [Medline] [CrossRef]

7) Richardson CA, Snijders CJ, Hides JA, et al.: The relation between the transversus abdominis muscles, sacroiliac joint mechanics, and low back pain. Spine, 2002, 27: 399-405. [Medline] [CrossRef]

8) Ricci JA, Stewart WF, Chee E, et al.: Back pain exacerbations and lost productive time costs in United States workers. Spine, 2006, 31: 3052-3060. 
[Medline] [CrossRef]

9) Brumagne S, Janssens L, Knapen S, et al.: Persons with recurrent low back pain exhibit a rigid postural control strategy. Eur Spine J, 2008, 17: 1177-1184. [Medline] [CrossRef]

10) Katz JN: Lumbar disc disorders and low-back pain: socioeconomic factors and consequences. J Bone Joint Surg Am, 2006, 88: 21-24. [Medline] [CrossRef]

11) Dufour N, Thamsborg G, Oefeldt A, et al.: Treatment of chronic low back pain: a randomized, clinical trial comparing group-based multidisciplinary biopsychosocial rehabilitation and intensive individual therapistassisted back muscle strengthening exercises. Spine, 2010, 35: 469-476. [Medline] [CrossRef]

12) Yoo YD, Lee YS: The effect of core stabilization exercises using a sling on pain and muscle strength of patients with chronic low back pain. J Phys Ther Sci, 2012, 24: 671-674. [CrossRef]
13) Han G, Cho M, Nam G, et al.: The effect on muscle strength and visual analog scale pain of aquatic therapy for individuals with low back pain. J Phys Ther Sci, 2011, 23: 57-60. [CrossRef]

14) Lee JH, Fell DW, Kim K: Plantar pressure distribution during walking: comparison of subjects with and without chronic low back pain. J Phys Ther Sci, 2011, 23: 923-926. [CrossRef]

15) Hsieh CY, Adams AH, Tobis J, et al.: Effectiveness of four conservative treatments for subacute low back pain: a randomized clinical trial. Spine, 2002, 27: 1142-1148. [Medline] [CrossRef]

16) Hamaoui A, Do MC, Bouisset S: Postural sway increase in low back pain subjects is not related to reduced spine range of motion. Neurosci Lett, 2004, 357: 135-138. [Medline] [CrossRef]

17) Popa T, Bonifazi M, Della Volpe R, et al.: Adaptive changes in postural strategy selection in chronic low back pain. Exp Brain Res, 2007, 177: 411-418. [Medline] [CrossRef] 